\title{
Meeting the substance abuse treatment needs of lesbian, bisexual and transgender women: implications from research to practice
}

This article was published in the following Dove Press journal:

Substance Abuse and Rehabilitation

27 January 2012

Number of times this article has been viewed

\author{
Sally Stevens \\ Southwest Institute for Research \\ on Women (SIROW) and Department \\ of Gender and Women's Studies \\ (GWS), University of Arizona, \\ Tucson, AZ, USA
}

\begin{abstract}
Research on the incidence, etiology and substance abuse treatment needs of lesbian, bisexual and transgender (LBT) women is limited. Most research indicates higher levels of alcohol and drug abuse among these populations compared to their heterosexual counterparts, with recent research indicating that substance abuse is a particular concern for transgender individuals and an increasing problem among younger LBT individuals. Risk factors and reasons for substance abuse among sexual minority women are similar to those of heterosexual women, yet are substantially complicated by issues of family rejection and lack of social support, stigma and minority stress, as well as abuse and harassment. Historically, substance abuse prevention, early intervention, and clinical treatment programs were designed to meet the needs of the sexual majority population with relatively few programs designed to incorporate the specific needs of sexual minorities. This article reviews findings from previous studies and utilizes new data collected from community-based and residential substance abuse treatment programs to (1) examine issues relevant to LBT women and substance use, and (2) make recommendations for tailoring substance abuse treatment programs to meet the needs of these populations.
\end{abstract}

Keywords: lesbian, bisexual, transgender, substance abuse, family rejection, social support, stigma, minority stress, abuse, harassment

\section{Introduction}

Substance abuse is a major public health problem in the United States (US). A recent study released by the Substance Abuse and Mental Health Services Administration (SAMHSA) indicates that the prevalence of illicit drug use among Americans increased between 2008 and $2010 .{ }^{1}$ Almost $9 \%$ of the population, representing over 22 million individuals 12 years of age or older are current illicit drug users. Yet, the substance abuse treatment needs of Americans have generally gone unmet, with only $11.2 \%$ of those needing substance abuse treatment receiving treatment. ${ }^{1}$ The unmet treatment needs of lesbian, gay, bisexual and transgendered (LGBT) substance users is thought to be disproportionately high, although it is difficult to determine given that many large scale surveys and treatment studies do not inquire about sexual orientation and many LGBT individuals may not be comfortable reporting their sexual orientation status at treatment entry. ${ }^{2}$

From a historical perspective, substance abuse treatment was developed for adult heterosexual men without regard to non-normative sexuality, gender, age and cultural considerations. ${ }^{3,4}$ In the early 1990 s there was a concerted focus on developing and delivering women-centered substance abuse treatment, including residential programs for women and children. ${ }^{5}$ More recently, research and service providers have attended 
to the specific needs of adolescents, taking into account developmental stage, cognition, and the multiple systems of care in which youth participate (eg, medical, education, legal, familial). ${ }^{6}$ In addition, culturally competent programs have emerged for ethnic minorities - particularly for American Indians and Alaska Natives ${ }^{7}$ - as have specialized programs for sexual minorities. ${ }^{8}$

While debate in the literature exists as to whether the focus should be on providing specialized substance abuse treatment programs for LGBT individuals or whether the focus should be on training substance abuse counselors to better meet their needs within a mixed treatment setting, there is some agreement on the particular issues that face LGBT individuals. A few of these issues include family rejection and lack of social support ${ }^{9-11}$; stigma and minority stress; ${ }^{12-17}$ and abuse and harassment. ${ }^{18,19}$ Moreover, recent research has noted that these issues are often substantially amplified for transgender individuals, especially male to female transgender, and include increased health concerns such as victimization, homelessness, and risk for - and incidence of - human immunodeficiency virus (HIV/AIDS). ${ }^{20,21}$

Published research conducted on substance use among LGBT is informative, yet limited. ${ }^{22,23}$ Research that has been conducted is often hampered by small sample sizes, non-representative samples, challenges in defining sexual orientation (eg, sexual identity versus sexual behavior versus sexual preference), analysis issues (eg, combining lesbian and bisexual women into one category), and other methodological problems. ${ }^{12,24-28}$ Research on LGBT youth is further complicated by regulatory issues of requiring parental consent, particularly when the youth are not "out" to the parent(s) or guardian(s), which for some youth "coming out" could mean familial rejection and/or physical harm. ${ }^{23}$ Given the limited knowledge with regard to LBT substance users, the purpose of this manuscript is to review the existing literature and add new data in order to illuminate the risk factors associated with substance abuse for LBT women and to make recommendations for providing LBT-competent substance abuse treatment.

\section{Substance abuse and related issues for LBT women}

For the most part, past research indicates higher levels of alcohol and other drug (AOD) use among sexual minority populations when compared to heterosexuals. In attempting to understand the etiology of substance use among this population, researchers have looked at various risk factors for AOD use including issues of family rejection and lack of social support, stigma and minority stress, and harassment and abuse - issues which are examined in more detail below.

\section{Alcohol and drug use among LBT women}

Community-based studies that have compared prevalence rates and problems with AOD use among LBT and heterosexual women have generally concluded that LBT women have higher incidence of and greater problems associated with AOD use. 2,12,19,29 Moreover, meta-analyses looking at

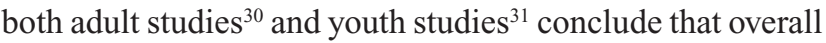
LBT females are more likely to report substance use compared to their heterosexual counterparts. Given the results from community-based research, it is not then surprising that LBT women enrolled in substance abuse treatment programs also report higher levels of substance abuse compared to heterosexual women, along with more severe problems associated with AOD use such as greater psychopathology and a greater need for medical services. ${ }^{26,32}$

Variations in research findings with regard to women and substance use have been noted given the complexity of the issue. For example, the setting in which subject recruitment occurs (eg, college campus versus community based) may influence outcomes. Research has found that lesbian and bisexual college students reported similar levels of alcohol use but elevated levels of drug use. ${ }^{33}$ This is in contrast to community-based studies that show higher levels of alcohol use among lesbian and bisexual women. Meanwhile, other studies that have examined differences in substance use across multiple sexual identity groups have found notable variations between groups. ${ }^{31,34}$ For example, research has found that bisexual women were more likely than heterosexual women to report marijuana use, while mainly (but not exclusively) heterosexual women were more likely than exclusively heterosexual women to report at-risk (binge) drinking. ${ }^{12}$ Other research has found that lesbian and bi-sexual women had greater odds of reporting current alcohol related problems compared to heterosexual women, ${ }^{2}$ and that LBT women were more likely to report heroin use a drug associated with needle-related health risks. ${ }^{26}$

New data from our own programs that work with LGBT and straight allied substance involved youth indicate a wide range in the frequency of substance use among participants. Data from the Prism Project (2003-2008) that enrolled 268 participants, aged 13-23 years, in a community-based LGBT youth center indicate that the majority of youth were not daily users of alcohol and/or illicit substances. Youth (47.8\% Caucasian) identified themselves as female 
$(51.1 \%)$, male $(42.2 \%)$, or transgender $(6.7 \%)$; and as either a heterosexual straight allied (24.3\%), bisexual (24.6\%), gay $(21.3 \%)$, lesbian $(13.1 \%)$, queer $(3.7 \%)$, questioning, not sure, or other $(6.4 \%)$, or unknown $(6.6 \%)$. Data, collected by external evaluators from the University of Arizona (UA) using a reliable and valid assessment, the Global Appraisal of Individual Needs (GAIN) ${ }^{35}$ indicate that one of five youth (19.4\%) reported not engaging in any AOD use during the 30 days prior to program enrollment, while $66.8 \%$ reported using $1-10$ days in the previous 30 days. Only $14.8 \%$ very were frequent users - using 11-30 days during the 30 days prior to enrollment. Variations in substance use by sexual identity groups were evidenced, with transgender participants reporting more recent drug use compared to LGB youth as noted in the project final evaluation report. ${ }^{21}$

New data is currently being collected from a second project, My Treatment Empowerment for Adolescents on the Move (iTEAM) (2009 and ongoing), at the same LGBT youth center. Using the GAIN, ${ }^{35}$ independent evaluators from the UA have collected data on 112 homeless/near homeless participants, aged 15-23 years. Youth (32.0\% Caucasian) identified themselves as female $(43.8 \%)$, male $(53.6 \%)$ or transgender $(2.7 \%)$. With regard to substance use, about half $(48.4 \%)$ reported not engaging in illicit substance use during the previous 3 months and less than half (43.2\%) reported not engaging in alcohol use in the 3 months prior to entering the program. ${ }^{36}$ Thus, while substance abuse may be a problem for many LGBT youth and young adults, a sizable percentage of LGBT youth are able to abstain from use.

Previously published substance use data from our adult women's-centered street outreach program, Community Outreach Project on AIDS in Southern Arizona for Women (COPASA for Women) (1998-2004), which enrolled 727 actively using crack cocaine and/or injection drug users, or female partners of injection drug users (68.0\% Caucasian), indicate significantly higher levels of substance use among lesbian and bisexual women $(n=117)$ compared to heterosexual women $(n=610)$. Several research assessments were used in this project including scales, matrixes and items from the Risk Behavior Assessment, a research instrument with good reliability and validity developed by National Institute on Drug Abuse research investigators. ${ }^{37,38}$ Data were collected by UA personnel who also facilitated a women'scentered HIV risk reduction intervention. Data from this project indicated that more lesbians $(54.2 \%)$ reported injection drug use compared to women who identified as heterosexual (40.7\%). ${ }^{39}$ Thus, health problems associated with needle use (eg, HIV, hepatitis C) are of particular concern for women who are substance-involved and identify as lesbians.

The prevalence rates of substance use and abuse among the LGBT population has been difficult to determine. ${ }^{40}$ Estimates of the overall LGBT population range from $2 \%$ to $13 \%$, with a recent study reporting that at least six million people living in the US are LGBT. ${ }^{41}$ Estimating the percentage of women who are lesbians or bisexuals, other research reports that perhaps $10 \%$ of adult American women are either lesbian or bisexual. ${ }^{42}$ Outreach programs for female drug users as well as residential substance abuse treatment programs for women report that enrollments include less than 5\% LBT women. ${ }^{39}$ Given that the majority of research suggests that AOD use is higher among LBT women, there appears to be an under-enrollment of LBT women in community-based and residential substance abuse treatment programs; a cause for concern with regard to (1) ineffective outreach and treatment engagement strategies, (2) deficiencies in providing appropriate screening at intake for sexual orientation, and (3) the need for LBT-competent substance abuse programs that prove to be effective in serving this population.

\section{Family rejection and social support}

The family of origin's response to disclosure of an LGBT identity can have a profound and long lasting effect. Responses can range from acceptance and support, to tolerance or avoidance, to rejection and abuse. Negative responses often have a devastating effect on the individual, particularly for youth who often do not have well-developed coping strategies, resources to be on their own, or other forms of social support. ${ }^{40}$ Most studies examining family rejection and self-disclosure do not distinguish between LGBT groups, rather they insist on LGBT as an identity monolith. Closer examination of data by subgroups would inform on the appropriateness of intervention strategies - fostering the potential to impact self-efficacy, improve mental health status, and reduce risk behaviors Additionally, most studies focus on LGBT adolescents and young adults, given the close relationship and need for immediate family at that age. Research has found that higher levels of family rejection during one's adolescence were significantly associated with poorer health outcomes for young LGBT adults aged 21-25 years compared with non-LGBT adults aged 21-25 years, and that they will also be 8.4 times more likely to have attempted suicide, 5.9 times more likely to report high levels of depression, 3.4 times more likely to engage in unprotected sexual intercourse, and 3.4 times more likely to have used illegal drugs. ${ }^{11}$ 
Many LGBT individuals experience high levels of anxiety about being rejected by friends and family members prior to disclosure, and for many rejection is what they experience once they do disclose identifying as LBGT. ${ }^{43} \mathrm{~A}$ recent study looks beyond disclosure and family rejection and examines the effect of the sheer number of rejecting reactions to disclosing one's minority sexual identity. ${ }^{44}$ Findings indicated that experiencing more rejecting reactions was associated with greater AOD use. However, the more accepting reactions a person experiences with regard to their disclosure protects from this negative effect of rejecting reactions for alcohol use but not drug use. These findings highlight the benefit that an accepting non-familial environment might have on the prevention of AOD use - calling for dedicated LGBT community youth centers and other LGBT-accepting social and treatment milieus.

New data from the Prism Project indicates that of the 268 participants, $68.0 \%$ reported that their family members feel very close to each other, $63.5 \%$ had family members that like to spend time with each other, and $60.6 \%$ had families that asked each other for help. Unfortunately, $17.7 \%$ of youth had families that did not fit any of the three positive descriptions. ${ }^{45}$ The majority of youth $(75.1 \%)$ had disclosed their sexual orientation to their families, and over half $(52.5 \%)$ were generally open with their family about their life. While these are somewhat promising data, concern remains for those $24.9 \%$ who had not disclosed their sexual orientation status to family and for the $47.5 \%$ who remain - in a more general way - closed to family members knowing about their life.

Newly analyzed data from the COPASA for Women street outreach program shows that of the 117 self-identified lesbian or bisexual women almost two-thirds (63.2\%) reported having moderate to extreme problems with family members, and almost half (45.1\%) reported moderate to extreme problems with non-family members. Moreover, new data from two adult women's residential substance abuse treatment programs (Mujer Sana 2002-2008; Herstory to Health 2008-present), which also used a modification of the Risk Behavior Assessment ${ }^{37,38}$ as the main data collection instrument denotes that of the 1,171 participants, 98 (8.4\%) self-identified as LBT women. The research assessment and was administered by UA personnel who served as both research interviewers and sexual health interventionist. Participants in Mujer Sana (61.0\% Caucasian) were recruited from women's residential substance abuse treatment programs, while participants in Herstory to Health $(40.0 \%$ Caucasian) were recruited from a residential substance abuse treatment program and through outreach to homeless women living on the streets. The percentage of women reporting moderate to extreme problems with family members was $80 \%$ for Mujer Sana, and $55.2 \%$ for Herstory to Health. The percentage of women reporting moderate to extreme problems with non-family members was $65.7 \%$ for Mujer Sana, and $63.3 \%$ for Herstory to Health. ${ }^{45}$ In part, the severity of drug use may be the complicating factor responsible for such a high percentage of LBT women reporting such familial and non-familial problems. Yet more in depth research needs to be conducted to understand the intersection of gender, sexual identity, family relations and substance use.

Newly analyzed data from the Mujer Sana and Herstory to Health projects also indicate differences between LBT and heterosexual women with regard to familial problems and social support from friends. These data show that a higher percent of LBT women have problems with family (55.2\%) compared to heterosexual women $(49.0 \%) .{ }^{46}$ However, a higher percentage of LBT women (80.6\%) report being satisfied/very satisfied with social support from friends when compared to heterosexual women (69.2\%). Perhaps LBT women are selecting a "family of choice" for support rather than relying on family members with whom they have problems.

\section{Stigma and minority stress}

Stigma is a personal quality or condition that is considered by the majority population to be deviant or in some way diminishes the person's status or worth. ${ }^{47}$ Stigma has been closely associated with conditions such as obesity, AIDS, mental illness, substance abuse, female gender, and sexual minority status. Stigmatized people often experience discrimination in the workplace, educational institutions, healthcare (including substance abuse treatment) and other life contexts and they may be the recipient of verbal and physical harassment. ${ }^{48}$ For LBT women who have a co-morbid mental health and substance abuse disorder, a quadruple stigma label applies (eg, female, sexual minority, mental health disorder, substance abuse disorder). Stigma may affect one's psychological health in which the person internalizes the stigma engendered by the majority or power position, adding additional stress and leading to increases in substance use and other high risk behaviors. ${ }^{49}$

Stigma faced by LBT substance using women lies at the intersection of gender and sexuality based oppression, and is intertwined with views about gender and behaviors appropriate for women. ${ }^{47}$ Historically, AOD use has been more acceptable for men as has been heterosexual promiscuity. ${ }^{50}$ Whether the stigma associated with non-normative sexual 
minority identity is religiously (morally) based or medically (pathologically) based, the social injustices experienced and internalized create pathways to substance use either directly or mediated though mental health symptoms - particularly anxiety and depression. ${ }^{13,49,50}$

Many heterosexual and LBGT substance users have endured stressful life situations with research indicating a correlation between substance abuse and stress. ${ }^{12,51}$ For LGBT individuals, minority stress is an added stressor. Minority stress is a phenomenon that applies to many groups with a minority identity (eg, gravely ill; handicapped; mentally ill). For LGBT individuals, they may experience physical and emotional stress as a result of being a sexual minority in a society that is anti-gay. ${ }^{52}$ Level of minority stress varies depending on the life context and experiences of the individual. It may also vary more generally between sexual minority groups. Research points to the concern that bisexuals may experience even higher levels of minority stress given the potential for marginalization from both gay and straight communities. ${ }^{53}$ This coincides with other research suggesting that bisexual women may be relatively more isolated given the lack of a congruent and visible community. ${ }^{54}$ Research findings with LBT women indicate stress as an important predictor of substance abuse, leading researchers to call for more systematic examinations of the relationship between substance use and minority stress in sexual minority women. ${ }^{12}$

New data from the iTEAM project suggest elevated stress levels for program participants. Childhood trauma, grief and loss, and harassment and abuse - both familial and from other sources - has been reported by both youth and adult LBT women. In a 90 minute focus group with 14 LBT women, the unsolicited term "stress" was used 24 times when discussing why LBT women used AOD or were at-risk for using AOD. Stress was mentioned in context of family, school, housing, peer relationships, and in association with being LBT women. While none of the focus group participants used the term "minority stress", the majority of the time in which stress was mention it was used in concert with sexual minority identity.

\section{Abuse and harassment}

Experiences of abuse and harassment are common among LGBT individuals. Like their heterosexual counterparts, a substantial number of substance users have lived in abusive or neglectful homes when growing up. Direct and mediated links (eg, depression) between childhood sexual abuse (CSA) and later substance use have been established for both heterosexual and LBT women. Data from women enrolled in substance abuse treatment programs consistently report higher levels of CSA than data from community samples. ${ }^{50}$ Estimates of prevalence rates for CSA vary widely but generally studies have reported higher levels of CSA for sexual minority women. ${ }^{55}$

Experiences of CSA vary as well. Data from the COPASA for Women project indicate that about half of the women who identified as lesbians reported some types of CSA. The type of CSA varied somewhat with $50.0 \%$ having been forced to see other's genitalia; $47.0 \%$ forced to show her genitalia; $41.9 \%$ talked dirty to or shown pornographic pictures; $59.8 \%$ touched in a sexual way; and $41.9 \%$ reporting that she had a penis or other object in her vagina. ${ }^{45}$ Past research suggests that some forms of CSA may be more traumatic than others, yet individual differences in responses to CSA are pronounced and thus clinicians need to assess for and address all forms of CSA. ${ }^{50}$

There is a reluctance to acknowledge intimate partner violence (IPV), particularly in lesbian relationships in which professionals, family and friends have a difficult time believing that women might inflict harm on another woman..$^{56}$ Estimates of IPV vary across populations, with estimates from primary healthcare setting ranging from $7 \%$ to $50 \% .{ }^{57}$ Incidence of IPV is particularly high among those who use AOD, ${ }^{58}$ and IPV acts vary considerably among substance users. ${ }^{59} \mathrm{~A}$ close examination comparing types of IPV experienced by substance using heterosexual versus lesbian women reveals differences in the types of abuse reported. Research has looked at both IPV victimization and perpetration, noting that lesbians reported less verbal abuse and less frequent threats with dangerous objects than heterosexuals, yet they demanded more obedience. ${ }^{39}$ Similar rates were reported for strangling and beating, leading the authors to consider "power" as a higher level construct over a "gender framework", and within which gender roles and expectations then become important.

While CSA, IPV and other forms of abuse and harassment are experienced by both heterosexual and sexual minority women, LBT women, especially youth, experience unique forms of abuse and harassment that are directly related to their sexual identity and behavior. Peer relationships are of maximum importance at the same time when youth are beginning to understand their own sense of sexuality. Concern over being rejected, harassed, ridiculed, and abused if they were "discovered" or if they disclosed their sexual minority orientation keeps teens silent. Yet, keeping silent about their sexuality results in isolation from their peers (and family). ${ }^{17}$ 
This fear is real and noted in numerous studies that have documented the percentage of LGBT youth who, due to their sexual orientation, have been verbally, physically or sexually assaulted, threatened, harassed, robbed or mistreated in numerous other ways both by peers and adults. ${ }^{17}$

Newly analyzed data from the Prism Project indicate that the majority of participants experienced harassment in school $(70.8 \%)$ or outside of school $(69.2 \%)$, with more than $50 \%$ reporting that they were harassed because of their sexual orientation or gender expression. Almost all (89.2\%) reported having been attacked or abused in their lifetime and a significant percentage (16.8\%) had been attacked or abused on more than five of the past 90 days. ${ }^{45}$

Newly analyzed data from the Herstory to Health project, indicate differences between LBT and heterosexual women with regard to physical and sexual abuse. LBT women more frequently report having been raped $(56.7 \%$ LBT vs $46.2 \%$ heterosexual); fear of future sexual abuse (64.2\% LBT vs 39.9\% heterosexual); and fear of future physical abuse (70.1\% LBT vs 58.9\% heterosexual). ${ }^{46}$ Abuse, harassment, and fear of future abuse and harassment is clearly an issue for all substance using women, and is even more elevated for LBT women - an issue that must be addressed in community centers and substance abuse treatment programs.

\section{Treatment recommendations Theory-driven and evidence-based} interventions in substance abuse treatment

During the past two decades, there has been an emphasis on documenting the effectiveness of theory-guided substance abuse treatment programs and on having treatment providers implement programs that have been assessed to be effective. SAMHSA's National Registry of Evidence-Based Programs and Practices ${ }^{60}$ makes available a menu of programs that have been assessed to be effective in addressing adolescent and adult substance abuse, with several documenting the efficacy in working with female and ethnic minority populations. Less is known about effective models of care for LBT women.

Unique risk factors for substance abuse for LBT individuals, such as family rejection and lack of social support, stigma and minority stress, and abuse and harassment, may call for unique theoretical perspectives to guide the development and delivery of substance abuse treatment interventions for them. Given that these unique risk factors are explicitly connected to sexual identity, theories that emphasize the nature of gender and gender identity may be superior for guiding the development and delivery of substance abuse treatment interventions for LBT women, including feminist theory, queer theory or transgender theory.

Feminist theory takes into account the legal, economic, and social context of women's lives and the multiple oppressions that women face. ${ }^{61}$ A person's gender is thought to be the superseding factor that identifies the person, their relationship to others, and their social experiences. ${ }^{62}$ Oppression is the prevailing element in substance abuse treatment interventions based on feminist theory, ${ }^{50}$ with interventions addressing both the structural (eg, legal, economic, social) as well as the personal (eg, relationships, abuse) issues in women's lives. Yet, while feminist theory addresses the issue of sexism and oppression it does not specifically address the heightened and unique issues of sexism and oppression experienced by LBT women as does queer and transgender theory.

Queer theory is a theoretical orientation for how identity is to be understood. Queer theory takes the position that gender roles, gender identity, and sexual orientations are social constructs and are open to questioning, subversion and self-construction. Queer theory challenges hetero-normative assumptions about sexuality, ${ }^{63}$ yet it has been criticized for retaining the gender binary that builds on the male versus female category construction. ${ }^{64}$ Queer theory thus may be off-putting to transgender individuals who may be living between the two binary gender categories.

In an effort to go beyond binary gender categories that remain in feminist theory and queer theory, transgender theory calls attention to the importance of physical embodiment in sexual and gender identity - integrating the self with socially constructive aspects of identity. ${ }^{64}$ To this author's knowledge, there are no theoretically guided or evidenced-based substance abuse treatment programs based on queer or transgender theory, although recommendations for working with LBGT substance users have been noted in the literature as discussed below.

\section{LBT status and substance abuse treatment practices}

Specialized substance abuse treatment programs that serve only LGBT individuals, while infrequent, are available in some communities ${ }^{8}$ and have been shown to effectively serve this population. Yet, some argue that substance abuse treatment providers should be challenged to meet the specific needs of LGBT substance users in a mixed setting, thus reducing further segregation and marginalization of LGBT individuals. This author's position is that we need both. Community-based programs specifically for LGBT adolescents and young adults are particularly important given the 
enhanced need to assist this young group with (1) disclosing their sexual minority identity, (2) issues of family rejection, (3) lack of housing and other stability factors (particularly those experiencing family rejection), and the (4) need for a safe environment given extreme levels of abuse and harassment due to their gender expression. However, given limited funding for substance abuse treatment and the fact that most LBT women will be treated in a setting that serves both LBT and heterosexual persons, clinical practice must provide LBT-informed care.

To identify and engage LBT AOD abusers in substance abuse treatment, communities must provide outreach and identification activities that are informative, inclusive, and sensitive to sexual orientation. The US education and medical systems may provide the best opportunity for outreach, identification, and an entrance pathway to treatment. School-based programs may best be implemented through coordination with community programs and volunteers who are trained in LGBT history and care. School counselors need to be informed on LGBT issues and should be knowledgeable about community-based service programs that meet the needs of LBT individuals. It should be noted, however, that our own work indicates that many programs report being sensitive to the needs of LBT women, yet LBT women enrolled in our programs often report differently. Thus, informed knowledge is best generated from LBT women themselves.

Medical providers, including primary care physicians, have the opportunity to identify and refer patients to substance abuse treatment or provide such treatment themselves. With the passage of health care reform, integration of substance abuse and mental health screening and treatment into primary and other health care settings is expected to move forward. Training for medical providers on the signs and symptoms of AOD abuse and the specific health care needs of LGBT populations is critical. A survey of deans at medical schools in the US and Canada finds that the medium amount of time undergraduate medical school education is dedicated to topics related to health care needs of LGBT patients is only 5 hours. ${ }^{65}$ An increase in LGBT-specific training for medical students, medical doctors and other health care providers could positively impact the number of LBT women receiving appropriate substance abuse treatment and consequently affect their overall health profile.

Successful treatment begins with a thorough assessment that is non-judgmental and inclusive of sexual orientation. LBT women entering treatment may be reluctant to disclose their sexual orientation. Data indicate that only asking about sexual behavior at treatment entry will miss over one-third of adolescents self-identifying as LGBT, calling for the inclusion of multiple questions that ask about sexual identity, sexual attraction, as well as sexual behavior. ${ }^{66}$ Importantly, initial (and ongoing) assessment should include questions about the "coming out" process, and specific experiences (positive and negative), specifically with regard to their sexual minority identity. A greater understanding of these issues will contribute to a more operative treatment plan.

During the assessment process as well as in the treatment milieu, counseling staff should refrain from making assumptions about health risks and social norms associated with identifying as an LBT person. For example, one should not assume that lesbians are not at risk for HIV. In fact, a substantial percentage of those identifying as lesbian women, and particularly bisexual women, have engaged in risky sex with at-risk men, and more lesbian women - compared to heterosexual women - report using drugs associated with needle use. Often pregnancy and parenting issues are overlooked even though data indicate that many LBT women have children or desire to have children. Data from our focus group with 14 LBT young women aged 15-23 years, indicate that two of the women had children and ten of the 14 planned to be a parent at some time in their life. Moreover, IPV is often not considered to be a "lesbian issue" even though most data indicate that lesbian women have equally high rates of IPV.

Language is an important aspect of treatment. Sexual slurs and LGBT jokes, while thought to be harmless, have a silencing effect and may keep the person from returning to treatment, and/or may be the basis for future AOD use. LBT-informed treatment includes asking clients the pronoun that they prefer to go by and encouraging other clients to use the pronoun of choice. Treatment workbooks and other program materials generally use heterosexual examples, thus conscious revisions to treatment curriculum materials are called for.

Finally, the unique issues that place LBGT individuals at risk for AOD use must be addressed directly in substance abuse treatment, including the issues articulated in this article: family rejection and lack of social support; stigma and minority stress; and abuse and harassment. Moreover, to prevent future AOD use, community-based recovery services and activities must be developed in which LBT women feel comfortable attending. Whether these are specific Alcoholics Anonymous or Narcotics Anonymous groups, drop in centers, school-based gay-straight alliances, recreational activities clubs, volunteer organizations, or other venues, unless LBT women feel welcomed, valued, supported and 
engaged in community, chances for relapse are significantly increased.

While resources and recommendations for providing substance abuse treatment for LBT substance users exist, the extent to which treatment facilities implement LGBTcentered approaches remains questionable. ${ }^{67,68}$ Research indicates that many counselors feel that their training is inadequate and that while, most counselors are accepting or neutral towards gay and lesbian clients, many have negative attitudes towards bisexual and transgender individuals. ${ }^{34}$ Training counselors to better understand the treatment needs of LBT women so they can provide competent treatment begins with having counselors examine their own biases towards LGBT individuals.

\section{Conclusion}

Research on LBT women has generally compared prevalence rates of AOD use and associated health behaviors between LBT women and their heterosexual counterparts. For the most part, the data indicate greater severity of AOD use and similar or higher levels of health-related risk behaviors. However, the settings in which data has been collected on LBT women is often at bars, health clinics, or treatment centers which do not result in representative samples of all LBT women. Data from our LGBT youth center indicate that while many participants are frequent substance users, a sizable percentage are not - calling into question the often assumed elevated prevalence of AOD use within the LGBT youth population. It may be that providing sexual minority youth with a safe and LGBT friendly community center may prevent future problems with AOD use, while also being able to offer LBGT-competent outpatient substance abuse treatment and referrals to more intensive treatment for those who need it.

While the etiology of substance use may be similar for heterosexual and LBT women, the added and elevated risk factors due to non-normative sexual orientation including family rejection and lack of social support, stigma and minority stress, and abuse and harassment must be addressed in substance abuse treatment. To effectively address these issues, counselor training is critical and an honest examination of personal bias is paramount to a counselor's ability to effectively work with these populations. While some recommend specialized and separate treatment programs for LBT women, given recent health care reform and the integration of health services into "health homes", specialized treatment may be rare. Thus, an urgent need for training exists - not only for health providers to be able to identify, refer and/or treat AOD abusers, but to meet the specific substance abuse treatment needs of sexual minority individuals.

Future research is critical including research that examines models of care designed to meet the needs of LBT women and based on gender theories that account for the overarching thesis of non-normative sexual identity. In looking at evidence of treatment effectiveness, separating out treatment effects for lesbians compared to bisexual and compared to transgender women will assist in determining how to better serve these non-monolithic groups. Finally, given that the vast majority of the research has been facilitated on the LBT women with substance use and other health-related problems, future research should also focus on non-substance involved, healthy, and empowered LBT women and their resiliency to substance use which, in turn, may further inform on effective treatment strategies.

\section{Acknowledgements}

The author would like to acknowledge the assistance of the numerous project participants as well as the research and clinical staff associated with each of the funded projects for their insights, time and dedication to the field of substance abuse treatment and related health issues.

Support for this research came from the US National Institute on Drug Abuse (Grant No 1R01 DA 10651) and the Substance Abuse and Mental Health Services Administration (Grant Nos 1 H79 TI 15863, 1 H79 TI 021367, 1 H79 TI 018730, and 1 H79 TI 14452). The views expressed in this article are those of the author and do not necessarily reflect the views of the funding entities.

\section{Disclosure}

The author declares no conflicts of interest in this work.

\section{References}

1. Results from the 2010 National Survey on Drug Use and Health: Summary of Substance Abuse and Mental Health Services Administration, NSDUH Series H-41, HHS Publication No. (SMA) 11-4658. Rockville, MD. http://oas.samhsa.gov/NSDUH/2k10NSDUH/2k10Results.htm\#7.3.2. Accessed September 8, 2011.

2. Drabble L, Trocki K. Alcohol consumption, alcohol-related problems, and other substance use among lesbian and bisexual women. J Lesbian Stud. 2005;9(3):19-30.

3. Goldbach GT, Holleran Steiker LK. An examination of cultural adaptations performed by LGBT-identified youths to a culturally-grounded evidence-based substance abuse intervention. J Gay Lesbian Soc Ser. 2011;23(2):188-203.

4. Stevens S, Andrade RAC, Ruiz BS. Women and substance abuse: Gender, age and cultural considerations. J Eth Subst Abuse. 2009;8: 341-358.

5. Stevens SJ, Wexler HK, editors. Women and Substance Abuse: Gender Transparency. Binghamton, NY: The Haworth Press, 1998;13(1/2): 235-249. 
6. Stevens SJ, Morral AR, editors. Adolescent Substance Abuse Treatment in the United States: Exemplary Models from a National Evaluation Study. Binghamton, NY: The Haworth Press, 1998:333-376.

7. Stewart-Sabin C, Chaffin M. Culturally competent substance abuse treatment for American Indian and Alaska Native youth. In: Stevens S, Morral AR, editors. Adolescent Substance Abuse Treatment in the United States: Exemplary Models from a National Evaluation Study. Binghamton, NY: The Haworth Press, 2003.

8. Hicks D. The importance of specialized treatment programs for lesbian and gay patients. J Gay Lesbian Psych. 2000;3(3/4):81-94.

9. Corliss HL, Austin SB, Roberts AL, Molnar BE. Sexual risk in mostly heterosexual young women: influence of social support and caregiver mental health. J Women's Health. 2009;18(12):2005-2010.

10. Price MF. Early trauma, societal oppression and coming out. J Gay Lesbian Psych. 2001;5(1):59-75.

11. Ryan C, Huebner D, Diaz RM, Sanchez J. Family rejection as a predictor of negative health outcomes in white and Latino lesbian, gay, and bisexual young adults. Pediatrics. 2009;123(1):346-352.

12. Hughes TL, Szalacha LA, McNair R. Substance abuse and mental health disparities: comparisons across sexual identity groups in a national sample of young Australian women. Soc Sci Med. 2010;71(4):824-831.

13. Jordan KM. Substance abuse among gay, lesbian, bisexual, transgender and questioning adolescents. School Psych Rev. 2000;29(2) 201-206

14. Koh AS, Ross LK. Mental health issues: a comparison of lesbian, bisexual, and heterosexual women. J Homosex. 2006;51(1):33-57.

15. Nemoto T, Operario D, Keatley J, Nguyen H, Sugano E. Promoting health for transgender women: transgender resources and neighborhood space (TRANS) program in San Francisco. Am J Public Health. 2005;95(3):382-384.

16. Sausa L, Keatley J, Operario D. Perceived risks and benefits of sex work among transgender women of color in San Francisco. Archives of Sexual Behavior. 2007;36(6):768-777.

17. Savin-Williams RC. Verbal and physical abuse as stressors in the lives of lesbian, gay male, and bisexual youth: associations with school problems, running away, substance abuse, prostitution, and suicide. J Consul Clin Psych. 1994;62(2):261-269.

18. Hyman B. Violence in the lives of lesbian women: implications for mental health. Social Work in Mental Health. 2009;7:1-3.

19. Ortiz-Hernandez L, Tello BL, Valdes J. The association of sexual orientation with self-rated health, cigarette and alcohol use in Mexican adolescents and youths. Soc Sci Med. 2009;69(1):85-93.

20. Dowshen N, Forke CM, Johnson AK, Kuhns LM, Rubin D, Garofalo R. Religiosity as a protective factor against HIV risk among young transgender women. J Adolesc Health. 2011;48:410-414.

21. Powell C, Stevens S, Korchmaros JD. Final Evaluation Report: EON-Prism Project: Capacity Enhancement to Improve and Integrate Culturally Relevant Substance Abuse and HIV/AIDS Services. Tucson, AZ. Southwest Institute for Research on Women, University of Arizona, 2008. http://sirow.arizona.edu. Accessed September 14, 2011.

22. Gillespie W, Blackwell R. Substance use patterns and consequences among lesbians, gays, and bisexuals. J Gay Lesbian Soc Ser. 2009; 21(1):90-108.

23. Mustanski B. Ethical and regulatory issues with conducting sexuality research with LGBT adolescents: a call to action for a scientifically informed approach. Arch Sex Behav. 2011;40:673-686.

24. Bauer GR, Jairam JA. Are lesbians really women who have sex with women (WSW)? Methodological concerns in measuring sexual orientation in health research. Women Health. 2008;48(4):383-408.

25. Carr CL. Bisexuality as a category in social research: lessons from women's gendered narratives. J Bisexuality. 2007;6(4):7-26.

26. Cochran BN, Cauce AM. Characteristics of lesbian, gay, bisexual, and transgender individuals entering substance abuse treatment. J Subst Abuse Treatment. 2006;30(2):135-146.

27. Korchmaros JD, Powell C, Stevens SJ. Chasing sexual orientation: A comparison of commonly-used single indicator measures of sexual orientation. Journal Homosex. In press.
28. Russell ST, Seif H. Bisexual female adolescents. J Bisexuality. 2002; 2:73-94.

29. Jaffe C, Clance PR, Nichols MF, Emshoff JG. The prevalence of alcoholism and feelings of alienation in lesbian and heterosexual women. In: Guss JR, Drescher J, editors. Addictions in the Gay and Lesbian Community. Harrington Park, NJ: The Haworth Press; 2000:25-35.

30. Meyer IH. Prejudice, social stress, and mental health in lesbian, gay, and bisexual populations: conceptual issues and research evidence. Psychol Bull. 2003;129(5):674-697.

31. Marshal MP, Friedman MS, Stall R, King KM, Miles J, Gold MA, et al. Sexual orientation and adolescent substance use: a meta-analysis and methodological review. Addiction. 2008;103(4):546-556.

32. Cochran SD, Mays VM, Sullivan JG. Prevalence of mental disorders, psychological distress, and mental health services use among lesbian, gay, bisexual adults in the United States. J Consult Clin Psychol. 2003;71(1):53-61.

33. McCabe SE, Boyd C, Hughes TL, d'Arcy H. Sexual identity and substance use among undergraduate students. J Subst Abuse. 2003;24(2):77-91.

34. Cochran BN, Peavy M, Santa AF. Differentiating LGBT individuals in substance abuse treatment: analyses based on sexuality and drug preference. J LGBT Health Res. 2007;3(2):63-75.

35. Dennis ML, Titus JC, White M, Unsicker J, Hodgkins D, Weber R. Global Appraisal of Individual Needs: Trainer's Manual and Resources. Bloomington, IL: Chestnut Health Systems, 2003. http://www.chestnut. org/LI/gain/index.html\#AdministrationManual. Accessed September 8, 2011.

36. Sinclair KO. iTEAM outcome report. iTEAM Biannual Retreat. Southwest Institute for Research on Women, University of Arizona. Tucson, AZ. 2011. http://sirow.arizona.edu. Accessed September 30, 2011.

37. Needle R, Fisher DG, Weatherby N, Chitwood D, Brown BS, Cesari H, et al. Reliability of drug users' self-reported HIV risk behaviors. Psych Addictive Behaviors. 1995;9:242-250.

38. Weatherby NL, Needle R, Cesari H, Booth R, McCoy CB, Waters JK, et al. Validity of self-reported drug use among injection drug users and crack cocaine users recruited through street outreach. Evaluation and Program Planning. 1994; 17:347-355.

39. Stevens S, Korchmaros JD, Miller D. A comparison of victimization and perpetration of intimate partner violence among drug abusing heterosexual and lesbian women. J Family Violence. 2010;25:639-649.

40. Substance Abuse and Mental Health Services Administration (SAMHSA) Center for Substance Abuse Treatment (2001). A Provider's Introduction to Substance Abuse Treatment for Lesbian, Gay, Bisexual and Transgender Individuals. Washington, DC: US Department of Health and Human Services Publication No. (SMA) 01-3498.

41. Snyder JE. Trend analysis of medical publications about LGBT persons: 1950-2007. J Homosex. 2011;58(2):164-188.

42. Shaw NS. New research issues in lesbian health. Women's Studies. 1989;17(1-2):125-137.

43. Benshoff JJ, Jankowski TO. The Rehabilitation Model of Substance Abuse Counseling. Belmont, CA: Brooks/Cole. 2000.

44. Rosario M, Schrimshaw EW, Hunter J. Disclosure of sexual orientation and subsequent substance use and abuse among lesbian, gay, and bisexual youths: critical role of disclosure reactions. Psychol Addict Behav. 2009:23(1):175-184.

45. Korchmaros JD, Stevens S. The Institute for LGBT Studies, Research Brief Series. University of Arizona, Tucson, AZ: 2010 http://lgbt. arizona.edu/research/health. Accessed September 9, 2011.

46. Andrade R. Herstory to Health. Community Research News, Summer IX. Tucson AZ. Southwest Institute for Research on Women, University of Arizona. 2010. http://sirow.arizona.edu/files/CRNSummer2010.pdf. Accessed September 15, 2011.

47. LaSala MS. Cognitive and environmental interventions for gay males: addressing stigma and its consequences. Fam Soc: Journal Contemp Human Serv. 2006;87(2):181-189.

48. Centers for Disease Control. Stigma and Discrimination, 2010. http:// www.cdc.gov/msmhealth/stigma-and-discrimination. Accessed September 15, 2011. 
49. Lombardi E, Bettcher T. Lesbian, gay, bisexual, and transgender/ transsexual individuals. In: Levy BS, Sidel VW, editors. Social Injustice and Public Health. New York, Oxford University Press. 2006:130-144.

50. Stevens SJ. Women and substance abuse: A gendered perspective. Fifth Annual Women's Mental Health Symposium. Tucson, AZ; 2006. http:// sirow.arizona.edu. Accessed September 14, 2011.

51. Brady KT, Sinha RS. Co-occurring mental health and substance use disorders: the neurobiological effects of chronic stress. Am J Psychiatry. 2005;162:1483-1493.

52. DiPlacido J. Minority stress among lesbians, gay men, and bisexuals: A consequence of heterosexism, homophobia and stigmatization. In: Herek G, editor. Stigma and Sexual Orientation Thousand Oaks, CA: Sage. 1998:138-159.

53. Weber GN. Using to numb the pain: substance use and abuse among lesbian, gay, and bisexual individuals. J Ment Health Counsel. 2008;30(1):31-48.

54. Israel T, Mohr JJ. Attitudes towards bisexual women and men: Current research, future directions. Journal of Bisexuality. 2004;4:117-134.

55. Hughes TL, Eliason M. Substance use and abuse in lesbian, gay, bisexual and transgender populations. J Prim Prev. 2002;22(3):263-298.

56. Merlis SR, Linville D. Exploring a community's response to lesbian domestic violence through the voices of providers: a qualitative study. J Fem Fam Ther. 2006;18(1/2):97-136.

57. Coker AL, Reeder CE, Fadden MK, Smith PH. Physical partner violence and Medicaid utilization and expenditures. Public Health Reports. 2004;119(6):557-567.

58. El-Bassel N, Gilbert L, Wu E, Go H, Hill J. Relationship between drug abuse and intimate partner violence: a longitudinal study among women receiving methadone. Am J Public Health. 2005;95(3):465-470.

59. Murphy B, Stevens SJ, McGrath R, Wexler HK, Reardon D. Women and violence: A different look. Drugs and Society. 1998;13(1/2):131-144.
60. Substance Abuse and Mental Health Services Administration. National Registry of Evidence-Based programs and Practices, 2011. http://nrepp. samhsa.gov. Accessed September 14, 2011.

61. Perez VV, Stevens SJ, Estrada BD. Feminist strategies for working with drug-involved women at risk for HIV: Outcomes and findings. The Symposium on Intervention Approaches with Women in Diverse Populations at Risk for Drug Use: Enhancing Outcomes in Women's Health: Translating Psychosocial and Behavioral Research into Primary Care, Community Interventions, and Health Policy Conference. Washington, DC; 2002. http://sirow.arizona.edu. Accessed September 10, 2011.

62. Harding S. The Science Question in Feminism. Ithaca, NY: Cornell University Press. 1986

63. Halperin D. Saint Foucault: Towards a Gay Hagiography. New York, Oxford University Press. 1995.

64. Nagoshi JL, Brzuzy S. Transgender theory: embodying research and practice. J Women Soc Work. 2010;25(4):431-443.

65. Obedin-Maliver J, Goldsmith ES, Stewart L, et al. Lesbian, gay, bisexual, and transgender-related content in undergraduate medical education. JAMA. 2011;306(9):971-977.

66. Leichtling G. Adolescent client responses to sexual orientation in the GAIN: What can we learn, what can we do? Joint Meeting on Adolescent Treatment Effectiveness. Baltimore, MD; 2010. http://www.jmate. org2012/PastMeetings.aspx. Accessed September 10, 2011.

67. Mathews CR, Selvidge M. Lesbian, gay, and bisexual clients' experiences in treatment for addiction. J Lesbian Stud. 2005;9(3):70-90.

68. Stevens S, Powell C, Korchmaros J. Adapting substance abuse and HIV interventions for LGBTQ youth and young adults. 2010 Joint Meeting on Adolescent Treatment Effectiveness. Baltimore, MD; 2010. http:/www. jmate.org2012/PastMeetings.aspx. Accessed September 10, 2011.
Substance Abuse and Rehabilitation

\section{Publish your work in this journal}

Substance Abuse and Rehabilitation is an international, peer-reviewed, open access journal publishing original research, case reports, editorials, reviews and commentaries on all areas of addiction and substance abuse and options for treatment and rehabilitation. The manuscript management system is completely online and includes a very quick and fair

\section{Dovepress}

peer-review system. Visit http://www.dovepress.com/testimonials.php to read real quotes from published authors. 